\title{
Costs and demand for legal support escalating
}

$\mathrm{M}$ ajor changes are required to ensure that legal protection for physicians remains affordable and accessible, says the Canadian Medical Protective Association. "We are in extraordinary times. We will be in extraordinary times. It is a difficult environment to find ourselves in," CMPA President Dr. Edward Crosby told 200 attendees at the annual meeting in Halifax.

Money is at the root of the problem. Although the number of lawsuits launched against Canadian doctors has declined $5 \%$ over the past 10 years (from 909 in 2005 to 866 in 2014), damages awarded by the courts have escalated. Median damages in Canada increased $117 \%$ in 10 years (from $\$ 99500$ in 2005 to $\$ 215700$ in 2014). Median legal expenses also grew by $63 \%$ (from $\$ 30100$ per case in 2005 to $\$ 49000$ a decade later).

"Whereas we knew costs were rising based on our models, we could not have predicted the magnitude of increases in damages awarded, in Ontario in particular," Dr. Hartley Stern, CMPA executive director and $\mathrm{CEO}$, said in an interview.

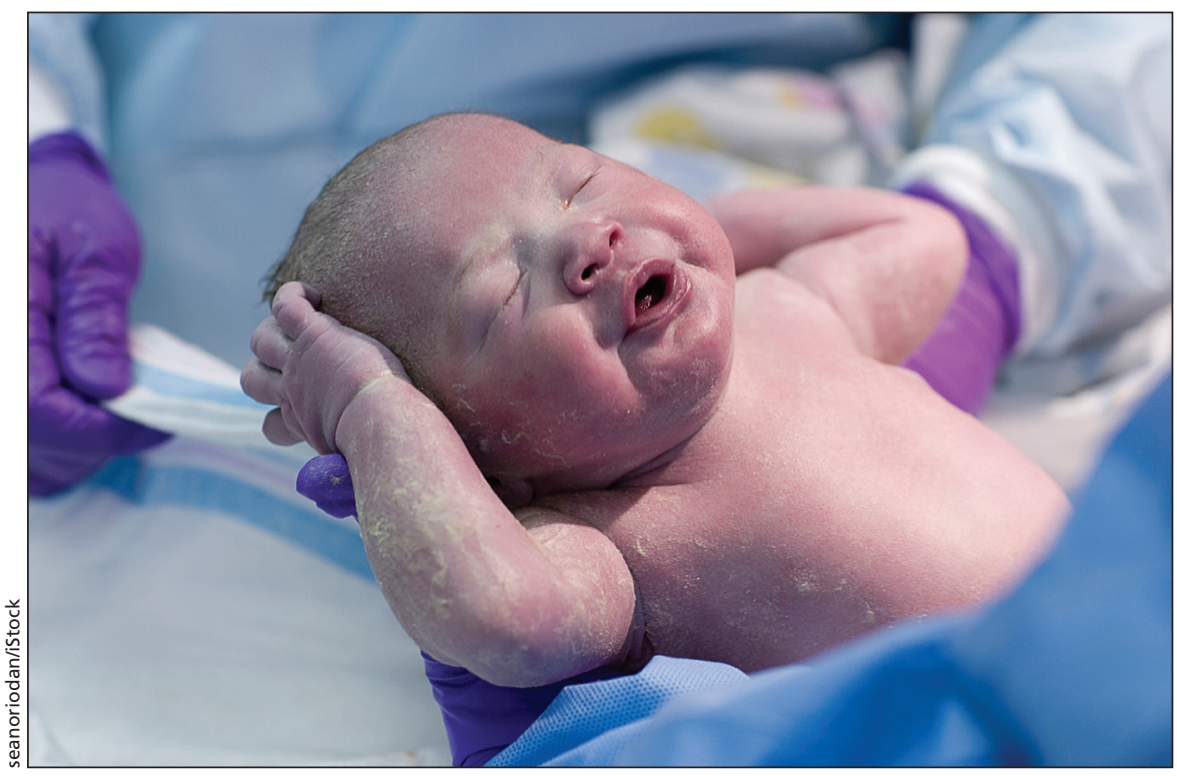

The CMPA is trying to reduce legal risks through education, which is presently focused on obstetricians, but will soon zero in on neurosurgeons and cardiovascular surgeons.

- a $100 \%$ increase since 2005 - and 1511 hospital-related matters.

The CMPA, which has more than 91000 members, is taking a twopronged approach to bringing costs back in line. First, it is advocating for judicial reform. Currently, under the doctrine of subrogation, governments

\section{Median damages in Canada increased $117 \%$ in 10 years.}

Physicians in Canada's largest province have experienced a $29 \%$ increase in the CMPA's aggregate fee requirement. As a result, in 2016, they will pay an additional $\$ 2225$ per physician.

At the same time as legal costs have increased, demand for services from the non-profit CMPA, which provides legal assistance to physicians and pays financial awards to successful plaintiffs, has skyrocketed. The number of physicians seeking advice or assistance in college-related matters has doubled while hospital-related matters have risen $75 \%$ over the past decade. In 2014, there were 4326 college-related matters brought before the association across Canada can have a successful plaintiff collect the cost of health care for the injured party now and in the future. When this happens, the association may raise member's insurance fees, which are usually paid by government. "It's circular money. It doesn't do any good," said Stern. "This makes no sense to us."

Changing the subrogation circle would not penalize patients or the awards that would be paid directly to them. Still, the argument, at present, is holding little sway with government. "These are changes that are difficult to get traction on," said Stern.

Easier to control may be the associa- tion's second area of emphasis: risk reduction. The CMPA has launched a program to reduce the number of incidents and accidents in the three highestrisk practice areas. At present, the educational initiative is focused on obstetricians, but will roll out to neurosurgeons and cardiovascular surgeons. In addition, plans are in the works to expand risk-reduction efforts among the general membership. Last year, 450 educational and training programs were offered to more than 25000 physicians and allied health professionals, including teaching faculty.

"The feedback from members attending these events is overwhelmingly positive," Crosby said at the Aug. 26 meeting.

While risk-reduction efforts may be popular and may be having an impact on the number of lawsuits launched, enhancing the safety of health care provision will not be a quick fix. "It's going to take awhile," said Stern. "We're in it for the long haul. These initiatives have 5- to 20-year horizon." - donalee Moulton, Halifax

CMAJ 2015. DOI:10.1503/cmaj.109-5154 